\title{
A RELAÇÃO ENTRE A ARTE E A AFETIVIDADE NO CONTEXTO DO ENSINO FUNDAMENTAL I
}

\author{
Maria José da Silva ${ }^{1}$ \\ Cristiano Leonardo Martins Oliveira ${ }^{2}$ \\ Ivanéia Maria de Lima $^{3}$ \\ Ronalda Adriana dos Santos da Silva ${ }^{4}$ \\ Diógenes José Gusmão Coutinho ${ }^{5}$
}

\begin{abstract}
RESUMO: objetivou-se investigar a quantidade de dissertações e teses, produzidas no período de 2010 a 2019, versando sobre a relação da arte e do afeto nos anos iniciais do ensino fundamental I. Buscou-se, especificamente, analisar os aspectos abordados nos trabalhos, compreender o estado da arte e do afeto como princípio básico no desenvolvimento da aprendizagem nos anos iniciais do ensino fundamental I. E, por fim, analisar as intervenções sugeridas nas produções estudadas. Identificou-se que as pesquisas são realizadas fragmentando os aspectos acometidos em relação à arte e o afeto. Foram encontrados 31 trabalhos 25, dissertações e 6 teses e com critérios de inclusão e exclusão, os trabalhos foram analisados respondendo as em foco. Pretendeu-se estatizar matematicamente os estudos através de uma revisão sistemática na literatura em uma pesquisa bibliográfica e quantitativa. Vislumbrou-se contribuir com sugestões de novas pesquisas com professores primários.
\end{abstract}

Palavras-chave: Arte. Afetividade. Ensino fundamental.

\footnotetext{
${ }^{1}$ Pós graduada em psicopedagogia clínica e institucional, pela instituição Jose Lacerda FilhoFAJOLCA. mestranda internacional em ciências da educação, pela faculdade Atenas College University. E-mail: mariajose-045@hotmail.com.

2 Graduação: Licenciatura Plena em Geografia Instituição: FAMASUL- Faculdade de Formação de Professores da Mata Sul Especialização: Psicopedagogia Clínica e Institucional Instituição: FAJOLCA- Faculdade José Lacerda Filho de Ciências Aplicadas e mestrando internacional em ciências da educação, pela faculdade Atenas College University. E-mail: cristianolmoliveira@gmail.com.

${ }^{3}$ Graduada em pedagogia pela Universidade Vale do Acaraú-UVA, Especialização em Gestão Escolar pela Faculdade Pitágoras de Belo Horizonte, mestranda internacional em ciências da educação, pela faculdade Atenas College University. E-mail: ivaneialima36@gmail.com.

${ }^{4}$ Graduação curso de licenciatura plena em pedagogia - Universidade Estadual Vale do Acaraú, pós-graduação lato sensu em gestão e psicopedagogia institucional - faculdade europeia de administração e marketing, mestranda internacional em ciências da educação, pela faculdade Atenas College University. E-mail: adriana-santos2011@hotmail.com.br.

${ }^{5}$ Graduado em Biologia pela UFRPE. Doutor em Biologia pela UFPE. Professor do Mestrado ALPHA. E-mail: alphadiogenes@gmail.com.
} 


\title{
THE RELATIONS BETWEEN ARTS AND AFFECTIVITY IN ELEMENTARY SCHOOL TEACHING
}

\begin{abstract}
Our target was to investigate the number of theses and dissertations produced between 2010 and 2019, about the relations of arts and affectivity in the early years of elementary school. We specifically seek to analize the aspects covered by the pubblications, to understand the role of arts and affectivity as a basic principle in the development of learning in the innitial years of elementary school. And lastly, analyze the changes and interventions suggested in the studied pubblications. It was identified that the researches was done breaking the apscts between arts and affectivity. It was found 31 works, being 25 dissertations and 6 theses, and with inclusion and exclusion criteria, the pubblications was analyzed asking with focus. It was intended to mathematically statify the studies, through a systematic revision in the literature, in a bibliographic and quantitative research. It was glimpsed to contribute with suggestions of new researches with techers and possible interventions
\end{abstract}

Keywords: Arts. Affectivity. Elementary School.

\section{INTRODUÇÃO}

A aprendizagem escolar é um fator muito preocupante, é um processo que depende da combinação coordenada de múltiplos fatores: genéticos, afetivos, neurobiológicos, psicoemocionais, socioculturais, pedagógicos, institucionais e familiares. Portanto, é um tema recorrente nos estudos há muito. Discentes que enfrentam diversas situações precárias podem representar impactos negativos que interferem no seu ensino- aprendizagem. $E$, podem também desestimular o professor em sua prática pedagógica.

Dessa forma, precisamos entender cada eixo citado e que possa ser influenciador e o mais importante passo a passo para tomar medidas preventivas e remediadoras para tais dificuldades (VIGOTSKY, 2001, p. 63).

Atrelado a isso, segundo estudiosos, ainda se encontram diversas crianças com grandes dificuldades no processo da aprendizagem. Entretanto, mesmo compreendendo a influência da arte e do afeto na vida do discente, ainda se persegue em pesquisa, as grandes dificuldades na aprendizagem em todos os segmentos de ensino e sob a luz de vários aspectos acometidos com diversos problemas, queixas e diagnósticos, em um misto de desinteresse e falta de 


\section{Universidade do Extremo Sul Catarinense \\ Revista Ibero-Americana de Humanidades, Ciências e \\ Educação \\ UneSC Produção e democratização do conhecimento na lbero-América}

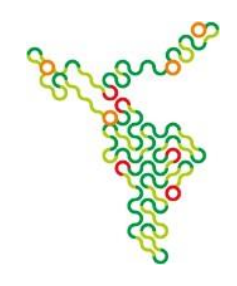

estímulo que os afastam da escola e o querer aprender. E poucas são as políticas públicas direcionadas para esse fenômeno recorrente.

Nesse contexto, podemos entender que a aprendizagem é um processo dinâmico e interativo do discente com o mundo que o cerca, buscando a apropriação de conhecimentos e estratégias adaptativas a partir de suas iniciativas e interesses e dos estímulos que recebe de seu meio social. De acordo com Vigotsky (1998, p. 63) "o comportamento do homem é formado por peculiaridades e condições biológicas e sociais do seu crescimento".

A interação tem papel fundamental no desenvolvimento da mente. A partir da interação entre diferentes sujeitos se estabelecem processos de conhecimento e apropriação do mundo. $O$ conhecimento do outro social se torna extremamente significativo para crianças em desenvolvimento, pois assume o papel de meio de verificação das diferenças entre competências, permitindo formular hipóteses e avançar ideias, auxiliando na sua compreensão do mundo que os cerca.

Primeiro no nível social, e, depois, no nível individual; primeiro entre pessoas (Inter psicológica), e, depois, no interior da criança (intrapsicológica). Isso se aplica igualmente para atenção voluntária, para a memória lógica e para a formação de conceitos. Todas as funções superiores originam-se das relações reais entre indivíduos humanos" (VIGOTSKY, 1998, p. 75).

Portanto, a aprendizagem do discente, dentro e fora do ambiente escolar, deve ser apresentada integralmente, sendo imprescindível a boa relação de convivência com os demais discentes. Permitindo uma harmonização entre sentimentos de prazer e satisfação, evitando assim, os sofrimentos causadores das frustrações e desânimos.

Assim, atentou-se para a questão das pesquisas que são referentes ao afeto e a afetividade que fragmentam os aspectos da aprendizagem em sala de aula. Ou seja, pesquisam isoladamente cada aspecto acometido da arte e do afeto, e ainda, o fato da existência de poucos estudos, e o desinteresse de alguns professores das primeiras letras da escolarização.

No contexto da psicopedagogia a prática escolar por si só já tenta produzir, em sua dinâmica e, com ela, sentimentos acolhedores e de prazer, buscando simultaneamente respeito de diversos aspectos do processo de ensino- 


\section{Universidade do Extremo Sul Catarinense \\ Revista Ibero-Americana de Humanidades, Ciências e \\ Educação \\ UnesC Produção e democratização do conhecimento na lbero-América}

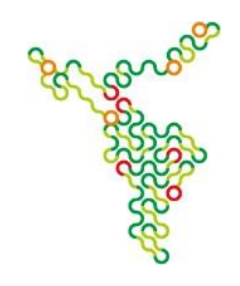

aprendizagem. Causando desejo em aprender. Logo, é possível aferir que o sujeito é elemento ativo na construção do próprio conhecimento, pois à medida que cria, relações e se comunica, desenvolve-se cultural e socialmente.

Segundo Rogoff (1998, p. 126) o aprendizado acontece a partir da apropriação participante:

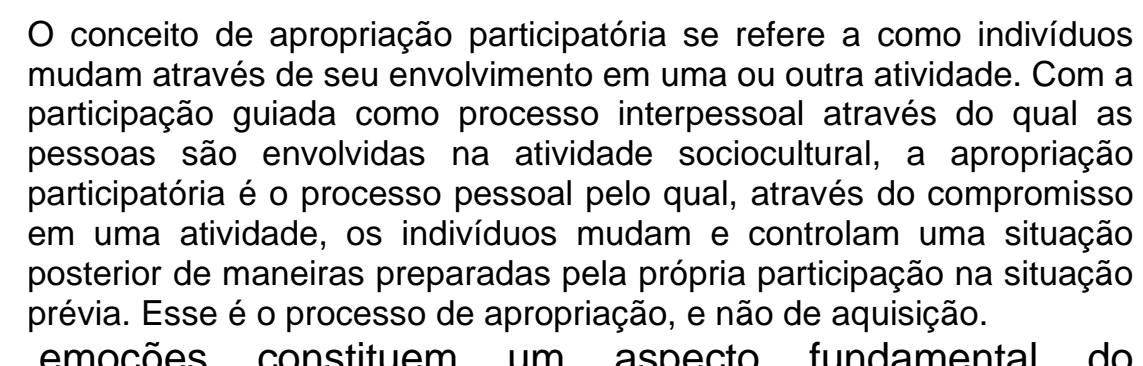

Assim, as emoções constituem um aspecto fundamental do desenvolvimento humano causando no discente um sentimento de prazer e satisfação nas demonstrações da arte e o quanto os desenhos e as brincadeiras no ambiente escolar devem ser evidentes e valorizados dia a dia, buscando inúmeras habilidades e condições para suas criações e as relações inerentes a ele.

Portanto, nesta Revisão Sistemática da Literatura e tendo como principal critério de inclusão os professores dos anos iniciais da escolaridade, objetivou-se evidenciar trabalhos com foco neste segmento de ensino. Elencando quais os fatores de acometimento no ensino da arte e na afetividade, tendo a prática docente como cenário, são mais apontados nos estudos encontrados, identificando as lacunas existentes e visando intervenções e novas pesquisas que preencham estas lacunas.

\section{MATERIAIS E MÉTODOS}

Tratou-se de uma revisão sistemática de literatura onde foi realizada uma busca eletrônica de dissertações e teses que versam sobe a arte e a afetividade como trampolins para o ensino em sala de aula, publicadas no período que compreende os anos de 2010 a 2019 indexados nas bases de dados nacionais, tais como: Biblioteca Digital Brasileira de Teses e Dissertações (BDTD) e Scientific Electronic Library Online (SciELO). 


\section{Universidade do Extremo Sul Catarinense \\ Revista Ibero-Americana de Humanidades, Ciências e \\ Educação \\ UnesC Produção e democratização do conhecimento na lbero-América}

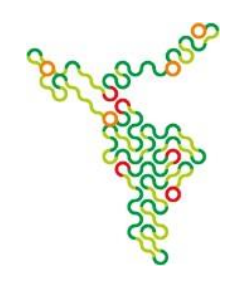

As pesquisas foram realizadas a partir dos descritores "Arte e Afetividade" e "Fundamental I", com professores dos anos iniciais da escolaridade, determinando-os como critérios de inclusão e exclusão. O material coletado foi descrito analiticamente.

De acordo com Pompeo (2009, p. 435) "Os estudos incluídos na revisão são analisados de forma sistemática em relação aos seus objetivos, materiais e métodos, permitindo que o leitor faça uma análise do conhecimento pré-existente sobre o tema investigado".

Trata-se da análise dos significados dos estudos pesquisados. Nos campos de buscas, foram indicadas as palavras-chave "Arte e Afetividade" e "Ensino Fundamental I", de maneira isolada, fragmentada e combinando-as. Foi filtrado, o campo "ano de publicação", para resultados entre os anos de 2010 a 2019.

Fez-se a opção pela revisão sistemática, pois se trata de um processo sistemático de busca, análise e descrição de um assunto, através da leitura e compreensão de um conjunto de publicações, tendo como objetivo levantar respostas para as questões propostas. É realizada uma análise e sintetização dos dados, apontando os resultados com clareza, e possibilitando a sua reutilização, aplicação e atualização. Decidiu-se analisar apenas as dissertações por terem sido encontradas publicações em todos os anos do recorte e em superior quantidade em relação às teses.

Dessa forma, para alcançar êxito, elaboramos a pergunta objeto como sendo "quais aspectos são estudados acerca da arte e da afetividade?" Para tanto, visitamos a literatura atual e histórica, selecionamos as produções limitando o tempo entre 2010 e 2019, coletamos os dados possíveis de respostas à pergunta e às hipóteses sobre os efeitos da arte e da afetividade neste segmento de ensino. Realizou-se uma avaliação na qualidade da metodologia desses estudos e, por fim, foi feita a sintetização dos dados coletados, para redigir e publicar os resultados. 


\section{Universidade do Extremo Sul Catarinense}

Revista Ibero-Americana de Humanidades, Ciências e

Educação

UneSC Produção e democratização do conhecimento na llbero-América

\section{RESULTADOS E DISCUSSÕES}

Foram encontrados 31 trabalhos publicados no período de 2010 a 2019. Dentre estes: 25 dissertações e 6 teses com predominância de dissertações no ano de 2018.

Quadro 1- Seleção dos trabalhos produzidos nos anos de 2010 a 2019

\begin{tabular}{|c|c|c|}
\hline ANO & DISSERTAÇÃO & TESE \\
\hline 2010 & 01 & 00 \\
\hline 2011 & 03 & 00 \\
\hline 2012 & 00 & 00 \\
\hline 2013 & 03 & 01 \\
\hline 2014 & 01 & 00 \\
\hline 2015 & 05 & 00 \\
\hline 2016 & 02 & 02 \\
\hline 2017 & 04 & 02 \\
\hline 2018 & 06 & 00 \\
\hline 2019 & 00 & 01 \\
\hline TOTAL & 25 & 06 \\
\hline
\end{tabular}

Fonte: Elaborado pela autora

No entanto, consideramos as de maior relevância de acordo com nossos critérios de inclusão e exclusão na abordagem da arte e da afetividade e das quais os docentes desenvolvem este trabalho, decidimos então, analisar apenas 8 dissertações.

Assim, esta revisão foi organizada em dois tópicos onde o primeiro contempla a compilação das obras pesquisadas, aspectos abordados e os segmentos de ensino da arte e da relação de afeto em sala de aula, descritos nos trabalhos, um diálogo com os autores destes trabalhos e a literatura fundamentadora do nosso estudo além das possíveis intervenções sugeridas pelos autores, que representaram os resultados.

\subsection{COMPILAÇÃO DAS OBRAS PESQUISADAS, ASPECTOS ABORDADOS E OS SEGMENTOS DE ENSINO INFLUENTE}

É importante esclarecer que a desigualdade entre os temas abordados e a quantidade de dissertações pesquisadas se deve ao fato de que alguns trabalhos 
abordam mais de um tema.

A maior parte dos trabalhos pesquisados se referia à formação e atuação dos professores atuantes no ensino fundamental, tratando das dificuldades na atuação, desde os obstáculos enfrentados nas escolas, até dificuldades em suas metodologias, adequações aos PCN (parâmetros curriculares nacionais), até os materiais utilizados e a necessidade de atualização dos professores.

Quadro 2- Aspectos abordados no trabalho

\begin{tabular}{|c|c|}
\hline FOCO CENTRAL & PUBLICAÇÕES \\
\hline Arte e afeto na construção do saber & 01 \\
\hline $\begin{array}{c}\text { Formação e atuação de professores do ensino } \\
\text { fundamental }\end{array}$ & 04 \\
\hline Desenvolvimento cognitivo & 02 \\
\hline Memórias do professor artista & 01 \\
\hline Narrativas dos alunos & 01 \\
\hline Total & 09 \\
\hline
\end{tabular}

Fonte: Elaborado pela autora

De acordo com as dissertações analisadas, os aspectos de formação/atualização dos professores foram os mais abordados, tendo sido observados em 4 delas. No entanto, em outras 3, observa-se a contribuição da arte para o desenvolvimento cognitivo dos alunos. No entanto, notou-se que não foram abordados os aspectos, arte e afetividade, juntos em um mesmo trabalho, o que nos aponta uma lacuna entre as pesquisas.

Dessa forma, a necessidade de se pesquisar conjuntamente os efeitos da arte e da afetividade no ensino das primeiras letras, se faz necessária. Pois, nesse segmento de ensino, as relações de afeto e cuidado, e as atitudes transformadoras, tais como imitações e assimilações, existem em conjunto, possibilitando uma melhor assimilação do mundo pelos alunos.

Nos primeiros anos do ensino fundamental, no início da formação do aluno, o educador atua como mediador de média um grupo de crianças agrupadas nas mais diversas relações sociais entre elas, o que possibilita interações.

Essas interações, segundo Piaget (1977) são responsáveis pelas estruturas mentais que são produzidas nessa etapa de adaptação com o exterior 


\section{Universidade do Extremo Sul Catarinense \\ Revista Ibero-Americana de Humanidades, Ciências e \\ Educação}

UneSC Produção e democratização do conhecimento na lbero-América

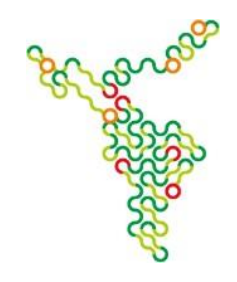

e interferem na construção de conhecimento do mundo. Assim sendo, entende-se que é nessa fase do ensino, ou seja, nos primeiros anos do ensino fundamental, que ocorre a maturação escolar.

Para que sejam dadas às crianças, oportunidades para aprender, o professor da Educação Infantil e dos primeiros anos do Ensino Fundamental, ou seja, das primeiras letras, precisa valer-se das relações de afetividade, e das artes enquanto ferramenta lúdica, para possibilitar o desenvolvimento das estruturas mentais dos alunos, habilitando-os assim, a construir o seu conhecimento a partir das trocas, assimilações adaptações e transformações.

Quadro 3- Compilação das dissertações estudadas

\begin{tabular}{|c|c|}
\hline ANO & DISSERTAÇÃO \\
\hline 2010 & 1 \\
\hline 2011 & 0 \\
\hline 2012 & 0 \\
\hline 2013 & 2 \\
\hline 2014 & 1 \\
\hline 2015 & 0 \\
\hline 2016 & 2 \\
\hline 2017 & 1 \\
\hline 2018 & 1 \\
\hline 2019 & 1 \\
\hline Total & 8 \\
\hline
\end{tabular}

A escola é um ambiente onde o sujeito deve se significar e tornar-se senhor do seu próprio destino cultivando sua felicidade sob os aspectos, físico, psicológico e social. Destaca-se a necessidade de adaptação por parte dos docentes à realidade dos alunos, aproximando-os e facilitando o processo de aprendizado. Neste contexto, a afetividade é, indiscutivelmente, ferramenta poderosa, conforme citado na maioria dos trabalhos analisados. Outros pontos elencados são: A arte e o lúdico, como ferramentas de facilitação do aprendizado.

A maioria dos trabalhos analisados concentra-se nas dificuldades do aprendizado e na formação e atualização dos professores que atuam no Ensino Fundamental.

Quadro 4- Relação Cronológica e principais abordagens das dissertações pesquisadas

\begin{tabular}{|l|l|l|}
\hline \multicolumn{1}{|c|}{ Autor/Ano } & \multicolumn{1}{|c|}{ Obra } & \multicolumn{1}{c|}{ Abordagens } \\
\hline $\begin{array}{l}\text { Oliveira, Maria Helena } \\
\text { Carvalho de }\end{array}$ & $\begin{array}{l}\text { A clínica da arte, dos afetos e dos } \\
\text { efeitos }\end{array}$ & $\begin{array}{l}\text { Esta pesquisa visa contribuir e } \\
\text { compreender como a arte e o } \\
\text { afeto ultrapassam as relações }\end{array}$ \\
\hline
\end{tabular}




\begin{tabular}{|c|c|c|}
\hline & & do fazer clínico e psicológico. \\
\hline Regina, Laima Irene Liblik & $\begin{array}{l}\text { Professores de arte dos anos } \\
\text { iniciais do ensino fundamental: } \\
\text { formação e atuação. }\end{array}$ & $\begin{array}{l}\text { Este trabalho deve-se atuar em } \\
\text { sintonia com os alunos de arte, } \\
\text { compreendendo seu papel e } \\
\text { cumprindo suas metas. A arte é } \\
\text { uma linguagem ilustrada que } \\
\text { tanto o aluno quanto o } \\
\text { professor aprendem ensina a } \\
\text { desenvolver saberes } \\
\text { diversificados tendo como } \\
\text { aliado as demonstrações de } \\
\text { afeto. }\end{array}$ \\
\hline Souza, Arlinda de Souza & $\begin{array}{l}\text { Horizontes entrecruzados: recepção } \\
\text { da arte literária nas séries iniciais do } \\
\text { ensino fundamental }\end{array}$ & $\begin{array}{l}\text { Esta pesquisa investiga a } \\
\text { necessidade da leitura nas } \\
\text { séries iniciais do ensino } \\
\text { fundamental elencando os } \\
\text { docentes para mediar no } \\
\text { processo de desenvolvimento } \\
\text { cognitivos, afetivos, culturais e } \\
\text { sociais proporcionando ao } \\
\text { discente leitura diária. }\end{array}$ \\
\hline Martins, Jordan Ávila & $\begin{array}{l}\text { Inventário do artista: um pequeno } \\
\text { relicário de grandes afetos. }\end{array}$ & $\begin{array}{l}\text { Este estudo analisa a memória } \\
\text { e a criação do artista, trazendo } \\
\text { em suas lembranças, histórias } \\
\text { reinventadas do passado } \\
\text { buscando como integrante } \\
\text { objetos do seu meio e outras } \\
\text { partes como relíquia } \\
\text { recompondo a arte na sua vida. }\end{array}$ \\
\hline Fernandes, Kelly Cristina & Teatro social dos afetos & $\begin{array}{l}\text { A pesquisa mostra os } \\
\text { obstáculos enfrentados nas } \\
\text { escolas comprometendo o } \\
\text { processo de ensino e } \\
\text { aprendizagem, transportando } \\
\text { as ações e práticas } \\
\text { pedagógicas dificuldades em } \\
\text { suas metodologias. Portanto a } \\
\text { arte é um meio fundamental no } \\
\text { processo cognitivo } \\
\text { psicológico da criança, tendo } \\
\text { como apoio em suas emoções } \\
\text { o afeto recebido. }\end{array}$ \\
\hline Brigatto, Agda Cristina & $\begin{array}{l}\text { Os caminhos do artista educador } \\
\text { em busca de imagens significativas }\end{array}$ & $\begin{array}{l}\text { Esse trabalho trata da relação } \\
\text { que se estabelece entre o } \\
\text { professor/artista e seus alunos, } \\
\text { durante as aulas de artes na } \\
\text { escola. São analisados vários } \\
\text { aspectos das vivências de } \\
\text { campo, tais como: O clima } \\
\text { afetivo, a intuição, os } \\
\text { sentimentos, as sensações, o }\end{array}$ \\
\hline
\end{tabular}

Revista Ibero-Americana de Humanidades, Ciências e Educação. Criciúma, v. 6.n.6, 2020. 
Universidade do Extremo Sul Catarinense

Revista Ibero-Americana de Humanidades, Ciências e

Educação

Unesc Produção e democratização do conhecimento na lbero-América

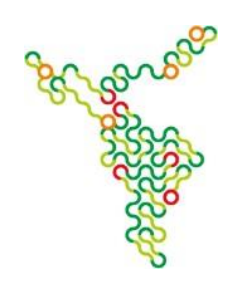

\begin{tabular}{|c|c|c|}
\hline & & $\begin{array}{l}\text { corpo subjetivo, os elementos } \\
\text { inconscientes, a intensa } \\
\text { mobilização criativa e a } \\
\text { inspiração mútua identificada } \\
\text { entre os sujeitos envolvidos. }\end{array}$ \\
\hline $\begin{array}{l}\text { Gresta, Luciana Maria } \\
\text { Rodrigues }\end{array}$ & $\begin{array}{l}\text { Narrativas infantis em cena: uma } \\
\text { experiência teatral no ensino } \\
\text { fundamental }\end{array}$ & $\begin{array}{l}\text { Este Trabalho procura } \\
\text { compreender como as } \\
\text { narrativas das crianças do } 50 \\
\text { ano do Fundamental são } \\
\text { transformadas em cenas, a } \\
\text { partir dos jogos teatrais, das } \\
\text { improvisações } \\
\text { experimentações. Privilegia a } \\
\text { escuta e a fala sensível dos } \\
\text { sujeitos, buscando a expressão } \\
\text { e a implicação dos mesmos no } \\
\text { processo vivenciado. A análise } \\
\text { metodológica se baseia nos } \\
\text { trabalhos Viola Spolin, Cecília } \\
\text { Warschauer e, principalmente, } \\
\text { René Barbier }\end{array}$ \\
\hline $\begin{array}{l}\text { Correa, Georgia Carolina } \\
\text { piacentini }\end{array}$ & $\begin{array}{l}\text { Teia Multicultural: a construção de } \\
\text { um modelo inovador na escola } \\
\text { brasileira }\end{array}$ & $\begin{array}{l}\text { A pesquisa aborda a } \\
\text { importância da arte, na } \\
\text { construção de um currículo } \\
\text { escolar e no processo de } \\
\text { formação de professores, e } \\
\text { demonstra como orientar e } \\
\text { subsidiar os conteúdos } \\
\text { propostos pela BNCC, } \\
\text { principalmente } \\
\text { propostos a partir de Projeto } \\
\text { Interdisciplinares, ampliando as } \\
\text { oportunidades de experiências } \\
\text { dos alunos e favorecendo o } \\
\text { despertar de dons e } \\
\text { habilidades. }\end{array}$ \\
\hline
\end{tabular}

Fonte: Elaborado pela autora

\section{CONSIDERAÇÕES FINAIS}

Observou-se que ainda são insuficientes as pesquisas com professores das primeiras letras (Educação Infantil e primeiros anos do Ensino Fundamental), enfocando o uso da Arte e da Afetividade, e como tal uso interfere na prática pedagógica e na qualidade do ensino.

Encontram-se diversas pesquisas focadas nas dificuldades do ensino, e na formação/atualização dos docentes. Entretanto, percebe-se uma lacuna, na qual não se observa o ensino em uma totalidade, considerando os aspectos psicológico e social, onde se destacam a utilização da afetividade e da arte, como 


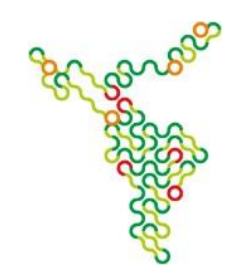

fatores que possibilitam uma melhor compreensão do mundo pelos alunos.

Conforme nos ensina Piaget (1979) a construção das estruturas mentais, e a compreensão do mundo pelos alunos estão diretamente ligadas à prática pedagógica dos professores das primeiras letras, assim é essencial buscar-se estratégias que possibilitem uma sua melhor atuação. A afetividade nos aproxima do aluno, e a arte, enquanto ferramenta variegada nos permite auxiliar na compreensão de mundo dos mesmos.

\section{REFERÊNCIAS}

BRIGATTO, Agda Cristina. Os caminhos do artista educador em busca de imagens significativas. Campinas, 2014.

CORREA, Georgia Carolina Piacentini. Teia Multicultural: a construção de um modelo inovador na escola brasileira. São Paulo, 2018.

FERNANDES, Kelly Cristina. Teatro social dos afetos. São Paulo, 2019.

GRESTA, Luciana Maria Rodrigues. Narrativas infantis em cena: uma experiência teatral no ensino fundamental. Brasília, 2016.

MARTINS, Jordan Ávila. Inventário do artista: um pequeno relicário de grandes afetos. Pelotas, 2017.

OLIVEIRA, Maria Helena Carvalho de. A clínica da arte, dos afetos e dos efeitos. São Paulo, 2013.

PIAGET, Jean. $O$ desenvolvimento do pensamento: equilibração das estruturas cognitivas. Lisboa: Dom Quixote, 1977.

PIAGET, Jean. Aprendizagem e Conhecimento. Rio de Janeiro: Freitas Bastos, 1979.

REGINA, Laima Irene Liblik. Professores de arte dos anos iniciais do ensino fundamental: formação e atuação. São Paulo, 2013.

ROGOFF, B. Observando a atividade sociocultural em três planos: apropriação participatória, participação guiada e aprendizado. Porto Alegre, 1998.

SOUZA, Arlinda de Souza. Horizontes entrecruzados: recepção da arte literária nas séries iniciais do ensino fundamental. Brasília, 2010.

VIGOTSKY, L. S. Psicologia pedagógica. São Paulo: Martins Fontes, 2001.

VIGOTSKY, L. S.; COLE, M. A formação social da mente: o desenvolvimento dos 
Universidade do Extremo Sul Catarinense

Revista lbero-Americana de Humanidades, Ciências e

Educação

UneSC Produção e democratização do conhecimento na lbero-América

processos psicológicos superiores. 6. ed. São Paulo: Martins Fontes, 1998. 